Obere Extremität 2021 • 16:265-271 https://doi.org/10.1007/s11678-021-00659-4 Received: 27 April 2021 Accepted: 26 July 2021

Published online: 3 September 2021

(c) The Author(s) 2021

\section{Supplementary Information}

The online version of this article (https:// doi.org/10.1007/s11678-021-00659-4) contains supplementary material, which is available to authorized users.

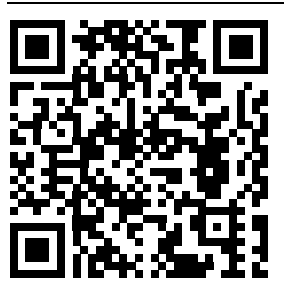

Scan QR code \& read article online

\title{
Establishing an institutional reverse total shoulder arthroplasty registry
}

Philipp Kriechling (D) - Manuel Waltenspül · Samy Bouaicha · Karl Wieser

Department of Orthopedics, Balgrist University Hospital, Zurich, Switzerland

\section{Abstract}

Background: The number of implanted reverse total shoulder arthroplasties (RTSA) is increasing worldwide. To improve patient care, institutional and national arthroplasty registries are being established worldwide to record outcome data. This article aims to describe the setup of an RTSA database in a high-volume university orthopedic hospital.

Methods: All patients who received an RTSA at the authors' tertiary referral hospital have been followed and individual datasets have been systematically recorded in a REDCap database since 2005. The data are captured longitudinally as a primary preoperative survey and as a regular or irregular postoperative follow-up. All baseline demographic data, patient history, surgical details, arthroplasty details, adverse events, and radiographic and clinical outcome scores (Constant-Murley score, Subjective Shoulder Value, range of motion) are recorded.

Results: A total of 1433 RTSA were implanted between January 2005 and December 2020. Of these, 1184 (83\%) were primary implantations and 249 (17\%) were secondary cases. The cohort had a mean age of $70 \pm 10$ years, was $39 \%$ male, and was classified ASA II in $59 \%$. The lost to follow-up rate was $18 \%$ after 2 years, $22 \%$ after 5 years, and $53 \%$ after 10 years. The overall complication rate with 2 years minimum follow-up was $18 \%$ (156/854 shoulders) with reintervention in 10\% (82/854 shoulders).

Conclusion: A well-managed institutional arthroplasty registry, including structured clinical and radiological follow-up assessments, offers the opportunity for high-quality long-term patient and arthroplasty outcome analysis. Such data are not only helpful for analyzing patient outcome and implant survival, but will be increasingly important to justify our daily clinical practice against different stakeholders in the various health care systems.

\section{Keywords}

Rotator cuff injuries - Quality of health care · Database · Postoperative complications - Treatment outcome

With an expanding number of implanted reverse shoulder arthroplasties (RTSA) worldwide, a systematic collection of baseline data and outcome parameters is essential to improve the quality of patient care. Institutional arthroplasty registries are helpful for standardized data collection and analysis. Since the setup of an arthroplasty registry is laborious, the number of large databases is limited worldwide. This article presents the development of an RTSA database containing currently 1433 shoulders, and is intended to provide sufficient informa- tion to build a standardized institutional registry.

In 1987, reverse total shoulder arthroplasty (RTSA) with a distalized and medialized center of rotation was introduced by Grammont to treat cuff tear arthropathy [13]. The satisfying clinical results led to widespread use of RTSAs, with an increasing expansion of indications $[2,9]$. In addition to the initial indication for cuff tear arthropathy, RTSAs are now used to treat massive rotator cuff tears, primary osteoarthritis, humeral 
head necrosis, shoulder instability, primary and secondary humeral fractures, rheumatoid arthritis, and serve as a reliable revision option. The wide range of applications and an aging population have led to a tremendous increase in implanted RTSAs worldwide [17]. The number of implanted reverse arthroplasties now exceeds the number of anatomical arthroplasties in most countries [6]. Despite increasing implantation numbers and various arthroplasty designs, a relatively high complication rate of up to $24 \%$ has been reported in the literature [29].

These adverse events significantly influence patients' outcomes and safety. Athorough evaluation of outcomes, complications, reoperations, and implant survival is essential for patient care quality.

Monocentric and multicentric databases as well as national registries have been established to collect outcome data, but they vary widely in terms of the quality and quantity of collected data. Databases will become increasingly important in the future to improve patient care. However, only a few studies exist on the development, design, and requirements of reverse shoulder arthroplasty registries [22].

The following article presents the setup of an institutional RTSA database using REDCap $[14,15]$ in a tertiary referral, highvolume orthopedic university hospital in Europe. This article aims to describe the standardized design, the different strategies for data collection, and some exemplary outcome data illustrating the scientific potential of such a database.

\section{Methods}

\section{Ethical approval}

The anonymous data collection and the study publication were approved by the cantonal ethics committee of the University of Zurich (ID 2018-01494) and conducted following the Helsinki Declaration. Each patient treated at the clinic signed consent for further use of data for research following a detailed explanation.

\section{Inclusion criteria}

All patients who received RTSA at the authors' tertiary referral center Balgrist Uni- versity Hospital as of January 2005 were potentially included in the database. Inclusion criteria were informed consent, patient age over 18 years, no pregnancy, and physical and mental ability to receive the follow-up examinations. Inclusion in the arthroplasty register could be withdrawn at any time.

\section{Surgery}

All arthroplasty-related information was captured. The main implant used was the Anatomical/Reverse RTSA manufactured by Zimmer/Biomet (Warsaw, IN, USA) as introduced in 2005 in the institution. Total joint replacement was performed by fellowship-trained staff shoulder surgeons of the authors' academic unit. The surgical procedures were standardized, with patients mostly receiving general or regional anesthesia with an additional interscalene catheter. The patients were placed in a beach chair position, antibiotic prophylaxis with cefuroxime (Fresenius Kabi, Switzerland) was administered $30 \mathrm{~min}$ before skin incision, and draping was performed using three rectangular drapes.

A deltopectoral approach was used in the vast majority of patients, leaving the cephalic vein laterally.

For primary RTSA implantation, the humeral head was resected, and for revision surgery, the prosthesis was removed if necessary. Well-fixed humeral stems allowing conversion to RTSA remained in situ whenever possible. The humeral stem was prepared to fit the planned implant size in 0 to $20^{\circ}$ of retroversion. The glenoid was reamed to create a flat surface. In revision cases of anatomical shoulder arthroplasties, previous removal of the components was primarily necessary. The baseplate was implanted with a neutral version and neutral to slight inferior inclination not exceeding $10^{\circ}$. If possible, transosseous subscapularis refixation using No. 2 FiberWire (Arthrex, Naples, FL, USA) was carried out. Aftercare consisted of wearing a sling for 6 weeks, allowing passive mobilization and minimal active use of the arm. Active range of motion exercises were carried out without weight through weeks 7 to 12 .
Clinical and radiographic follow-up examination

All patients underwent a standardized preoperative examination by the treating surgeon and an orthopedic resident. The preoperative data assessment included medical history, previous surgeries and comorbidities, standardized assessment of shoulder motion, the absolute and relative Constant-Murley score, and the Subjective Shoulder Value (SSV) $[5,10]$. The preoperative radiologic examination included three standardized planes (anteroposterior, Neer view, and lateral axillary view) in the standing position and supine computed tomography, including the medial border of the scapula. Stem size was preoperatively planned on plain radiographs using dedicated software and glenoid orientation (version and inclination) was planned on the CT scan (mediCAD ${ }^{\circledR}$ Hectec $\mathrm{GmbH}$, Altdorf, Germany).

The patients were followed up at 6 weeks, 18 weeks, 1 year, 2 years, and every 2 to 3 years thereafter. The followup was conducted by a study nurse under the supervision of an orthopedic staff member specializing in shoulder surgery. All patients underwent clinical examination using the absolute and relative Constant-Murley score [5, 10], including full assessments of range of motion and abduction strength using a validated dynamometer. Furthermore, the SSV [10] was assessed and patients were asked to rate their satisfaction with the outcome of the procedure. The radiological examination included standardized X-rays in three planes.

\section{Data collection}

All data were captured in the clinical information system and REDCap (Research Electronic Data Capture; Vanderbilt University, Nashville, TN, USA). REDCap is a secure, web-based software platform designed to support data capture for research studies, providing 1) an intuitive interface for validated data capture; 2) audit trails for tracking data manipulation and export procedures; 3) automated export procedures for seamless data downloads to common statistical packages; and 4) procedures for data integration and interoperability with 


\begin{tabular}{|c|c|c|c|c|c|c|c|c|c|c|}
\hline Data Collection Instrument & basisdata & $\begin{array}{l}\text { Revision } \\
\text { Surgery }\end{array}$ & $\begin{array}{l}\text { Follow-up } \\
\text { unregular }\end{array}$ & Y1 & Y2 & Y3 & Y4 & Y5 & Y10 & Y15 \\
\hline My First Instrument & ○ & & & & & & & & & \\
\hline -- BASE --- & 0 & & & & & & & & & \\
\hline Primary Base (Study Nurse) & 0 & & & & & & & & & \\
\hline Secondary Base (Research Fellow) & 0 & & & & & & & & & \\
\hline -- FOLLOW-UP --- & $\odot$ & & & & & & & & & \\
\hline Outpatient Clinic Report & 0 & 0 & O & 0 & 0 & 0 & 0 & 0 & O & O \\
\hline Constant Score & ○ & ○ & ○ & 0 & O & ○ & ○ & ○ & ○ & O \\
\hline Lost to follow-up & 0 & & & & & & & & & \\
\hline Complication & 0 & & & & & & & & & \\
\hline Radiographic follow-up & 0 & 0 & 0 & O & O & 0 & 0 & ○ & ○ & O \\
\hline -- REINTERVENTION -- & 0 & & & & & & & & & \\
\hline Revision Surgery & & ○ & & & & & & & & \\
\hline
\end{tabular}

Fig. $1 \triangleleft$ REDCap data capture form. The longitudinal course is arranged horizontally, which allows entering of the annual controls and unplanned events in unlimited numbers. Vertically, the different events are listed. Some of them are repeated according to the annual follow-up (outpatient clinic report, Constant score, etc.). (With kind permission from https://projectredcap.org). Yyear(s)

external sources. Study data were collected and managed using REDCap electronic data capture tools hosted at Balgrist University Hospital. At the time of this article's preparation, 5006 institutions from 141 countries were registered as REDCap users $[14,15]$.

Patients have been systematically recorded in the clinical information system at the timepoints defined above since 2005. Data collection is based on standardized recommendations [1, 23]. The exact database design is documented below.

\section{Database design}

Each operated shoulder was assigned a unique ID; thus, patients operated on both sides received two IDs. The database was set up longitudinally with the possibility of recording all annual controls as well as the preoperative examination. In addition to regular annual controls, there was the possibility to include unplanned events and reinterventions in unlimited numbers (- Fig. 1).

Follow-up includes the complete consultation report with diagnosis list, the total Constant-Murley scores including the range of motion and pain, the SSV, selected radiological parameters (e.g., notching, loosening, fractures) from continuously collected $\mathrm{x}$-rays at each consultation, the follow-up status (lost, death, next appointment), complications, and reinterventions.

The preoperative baseline data are more comprehensive and divided into primary and secondary (advanced) data. Basic data include gender, year of birth, body weight, height, body mass index, American Society of Anesthesiologists (ASA) classification, study participation agreement, and a few surgical details-date, indication, side, diagnosis, name of the procedure, implant manufacturer, type of stem, cementation, full surgical report.

The secondary baseline data are more extensive and are provided by shoulder research fellows. They include an exact breakdown of the surgical details as well as the prosthetic components including all sizes, accurate patient history, and radiological (x-ray and computed tomography) and laboratory chemical data. All data are provided in the Supplementary Material.

\section{Results}

\section{Basic characteristics}

Between January 2005 and December 2020, a total of 1449 RTSA were implanted in the authors' tertiary referral center and followed up continuously. Sixteen patients disagreed with undergoing analysis for studies, leaving a total of 1433 patients for further investigation. Patient characteristics and arthroplasty data are displayed in $\mathbf{0}$ Tables 1 and 2.

\section{Follow-up and mortality}

Of 1433 shoulders included in the database, 1212 received the arthroplasty 2 or more years ago (before December 31, 2018) with a mean follow-up of $59 \pm 35$ (24; 183) months.

An overall lost to follow-up rate of the cohort was reported in 390 patients (27\%) at a mean of $40 \pm 36(0 ; 169)$ months.
Death was the reason in 126 patients (140 shoulders, 36\%) after at a mean time of $60 \pm 37(3 ; 170)$ months postoperatively. The mean age at death was $79 \pm 10(41$; 97) years.

The period-specific lost to follow-up rate was $18 \%$ after 2 years, $22 \%$ after 5 years, and $53 \%$ after 10 years.

\section{Complications and reinterventions in primary RTSA}

As an example of the database's usability, the complication rate of primary implanted arthroplasties (without prior arthroplasty or surgical fracture treatment using plates) before August 2018 was analyzed. A total of 188 complications occurred (22\%) in 156 shoulders (18\%) and led to reintervention in 82 shoulders (10\%). These were distributed into $41 \%$ revisions (with a change of prosthetic components) and $59 \%$ reoperations (without change of prosthetic components). The main complications were acromial fractures (5.3\%), glenoid loosening (4.3\%), and RTSA instability (2.7\%). The main indications for reintervention surgery were glenoid loosening (2.7\%), instability (1.8\%), and acromial fractures (1.3\%).

After breakdown of the complications, clinical outcomes were compared with the rest of the primary RTSA cohort. Patients without a complication $(n=620)$ showed significantly better outcomes compared patients who sustained a complication, as reflected in the absolute Constant score $(67 \pm 14$ points vs. $45 \pm 20$ points, $p=0.00)$, relative Constant score $(81 \pm 16 \%$ vs. $57 \pm 24 \%, p=0.00)$, SSV ( $80 \pm 20 \%$ vs. $53 \pm 27 \%, p=0.00$ ), and constant pain 
Table 1 Basic demographic data of the cohort

\begin{tabular}{|c|c|c|c|}
\hline & All RTSA & Primary RTSA & Secondary RTSA \\
\hline Total shoulders & 1433 & $1184(83 \%)$ & $249(17 \%)$ \\
\hline Total patients & 1322 & 1094 & 242 \\
\hline Age at surgery & $70 \pm 10(24 ; 94)$ & $72 \pm 10(30 ; 94)$ & $65 \pm 10(24 ; 88)$ \\
\hline \multicolumn{4}{|l|}{ Gender } \\
\hline Male & $561(39 \%)$ & $449(38 \%)$ & $112(45 \%)$ \\
\hline Female & $872(61 \%)$ & $735(62 \%)$ & $137(55 \%)$ \\
\hline \multicolumn{4}{|l|}{ Side } \\
\hline Right & $851(59 \%)$ & $706(60 \%)$ & $144(58 \%)$ \\
\hline Left & $582(41 \%)$ & $478(40 \%)$ & $105(42 \%)$ \\
\hline$B M I\left(\mathrm{~kg} / \mathrm{m}^{2}\right)$ & $28 \pm 5(14 ; 63)$ & $27 \pm 5(14 ; 63)$ & $28 \pm 5(16 ; 44)$ \\
\hline Weight (kg) & $76 \pm 17(32 ; 159)$ & $75 \pm 17(32 ; 159)$ & $80 \pm 18(43 ; 154)$ \\
\hline Height (m) & $166 \pm 10(134 ; 200)$ & $165 \pm 10(134 ; 200)$ & $168 \pm 9(143 ; 197)$ \\
\hline \multicolumn{4}{|l|}{$A S A$} \\
\hline ASA I & $87(6 \%)$ & $71(6 \%)$ & $16(6 \%)$ \\
\hline ASA II & $836(59 \%)$ & $676(57 \%)$ & $160(65 \%)$ \\
\hline ASA III & $485(34 \%)$ & $417(35 \%)$ & $68(27 \%)$ \\
\hline ASA IV & $17(1 \%)$ & $13(1 \%)$ & $4(2 \%)$ \\
\hline ASA V & $1(0.1 \%)$ & $1(0.1 \%)$ & $0(0 \%)$ \\
\hline \multicolumn{4}{|l|}{ Smoking } \\
\hline Yes & $207(14 \%)$ & $159(13 \%)$ & $48(19 \%)$ \\
\hline Stopped & $157(11 \%)$ & $136(12 \%)$ & $21(8 \%)$ \\
\hline Never & 1017 (71\%) & $854(72 \%)$ & $163(66 \%)$ \\
\hline Unknown & $52(4 \%)$ & $35(3 \%)$ & $17(7 \%)$ \\
\hline No. of previous surgeries & $1 \pm 1(0 ; 12)$ & $0.6 \pm 1(0 ; 11)$ & $2 \pm 2(1 ; 12)$ \\
\hline No. previous surgeries & 771 patients (54\%) & $771(65 \%)$ & $0(0 \%)$ \\
\hline \multicolumn{4}{|c|}{$\begin{array}{l}\text { Primary RTSA was defined as all primary implantations without previous arthroplasty-related surg- } \\
\text { eries. The values are expressed as mean } \pm \text { standard deviation (minimum; maximum) } \\
\text { ASA surgical risk classification of the American Society of Anesthesiologists, BMI body mass index, } \\
\text { PY pack years, RTSA reverse total shoulder arthroplasty }\end{array}$} \\
\hline
\end{tabular}

score $(14 \pm 3$ vs. $11 \pm 4, p=0.00 ; 15$ as best value). The range of motion yielded significantly better values for flexion $\left(122 \pm 24^{\circ}\right.$ vs. $\left.88 \pm 38^{\circ}, p=0.00\right)$, abduction $\left(131 \pm 33^{\circ}\right.$ vs. $\left.89 \pm 43^{\circ}, p=0.00\right)$, and external rotation $\left(27 \pm 18^{\circ}\right.$ vs. $21 \pm 21^{\circ}$, $p=0.00)$.

\section{Discussion}

This study describes the setup of an RTSA database at a high-volume, tertiary referral orthopedic university hospital in Europe. RTSA patients have been followed up since 2005 and data recorded in the clinical information system. Since 2018, these data have been systematically transferred to REDCap to allow quick and standardized analysis. Currently, 1433 RTSA implantations are available for evaluation, of which $83 \%$ represent primary implantations without prior prosthetic surgery. All patients were followed up at regular intervals with clinical examination (including Constant-Murley score, SSV, range of motion) and standard radiographs. The mean follow-up of the cohort after a minimum of 2 years was $59 \pm 35$ months. Exemplary analysis of the complication rate of $18 \%$ and the reintervention rate of $10 \%$ emphasizes the importance of databases. Although these rates appear to be high, they are comparable with the current literature [29]. Specific follow-up studies should be conducted to identify possible causes and therapeutic algorithms.

Establishment of registries is an important tool in medicine for assessing patient care [21, 22]. In addition to databases for hip and knee arthroplasties, which have been established for many years, the widespread, systematic recording of RTSAs was started around the turn or the millennium. Comparable monocentric reg- istries also have case numbers close to 1500 arthroplasties [7, 11, 12]. The monocentric design has the advantage of a relatively standardized surgical technique, often with only a few different implants. This homogeneous patient care and uniform data measurement allows-beside a rather general implant survivorship analysis-a thorough outcome analysis and can be used to answer specific scientific questions.

Generalization of the data can be achieved by multicentric data collection or national registries (- Table 3; [20, 27]). Currently, the largest multicentric database includes more than 5000 RTSA implants from 40 different orthopedic surgeons investigating various questions [27]. Data quality in multicentric studies is highly dependent on the participating centers and can vary significantly in quality.

In contrast to local mono- and multicentric databases, national and international registries provide a significantly higher number of patients (- Table 3; [21]). Currently, the Australian registry includes the highest number of patients, with nearly 30,330 implanted primary RTSAs. However, in contrast to institutional databases, national registries record significantly fewer or even no clinical outcome parameters, as mainly only prosthetic survivorship and reintervention rates are assessed [21]. Standardized annual clinical and radiological follow-ups are usually reserved for local databases.

The current monocentric registry is one of the largest and enabled various analyses [3, 16, 17]. It is essential to highlight the additional expense of setting up a database for an institution, especially when a clinical examination is part of the follow-up assessment. Our patients are regularly monitored, which is time and resource consuming and might not be possible in every institutional setup and insurance system. A designated study nurse collects a concise set of data at every follow-up visit. Additional recorded clinical and radiographic data are contained in a standardized way by research fellows and are additionally gathered on a studyspecific basis. Once collected in REDCap, all data are available for any further study analysis. The data were therefore recorded 


\begin{tabular}{|c|c|c|}
\hline Total & 1433 & - \\
\hline \multicolumn{3}{|l|}{ Surgical indication } \\
\hline Primary implantation & 1184 & $100 \%$ \\
\hline Rotator cuff tear without osteoarthritis & 356 & $30 \%$ \\
\hline Rotator cuff tear with osteoarthritis & 297 & $21 \%$ \\
\hline Osteoarthritis & 177 & $15 \%$ \\
\hline Following ORIF & 113 & $10 \%$ \\
\hline Cuff tear arthropathy & 93 & $8 \%$ \\
\hline Fracture & 86 & $7 \%$ \\
\hline Instability & 35 & $3 \%$ \\
\hline Humeral head necrosis & 22 & $2 \%$ \\
\hline Other & 5 & $0.5 \%$ \\
\hline Secondary implantation & 249 & $100 \%$ \\
\hline Conversion of hemiarthroplasty & 114 & $46 \%$ \\
\hline Conversion of TSA & 87 & $35 \%$ \\
\hline Revision of RTSA & 42 & $17 \%$ \\
\hline Other & 6 & $2 \%$ \\
\hline Approach deltopectoral & 1401 & $98 \%$ \\
\hline No. of surgeons & 18 & - \\
\hline Manufacturer Zimmer/Biomet & 1401 & $98 \%$ \\
\hline \multicolumn{3}{|l|}{ Humeral shaft type } \\
\hline Standard stem & 1244 & $87 \%$ \\
\hline Fracture stem & 155 & $11 \%$ \\
\hline Revision stem & 23 & $2 \%$ \\
\hline Cementation used & 623 & $44 \%$ \\
\hline
\end{tabular}

in a standardized way to enable potential analysis in cooperation with other centers.

Only a few studies reporting on the setup of institutional RTSA databases exist in the literature. In 2020, the design of another monocentric shoulder prosthesis registry with nearly 1480 RTSAs was described [22]. Like our database setup, a normalized international consensus was used to classify adverse events [1] and radiological image data [8].

The authors are convinced that the collection of subjective and objective outcome parameters following surgical care will continue to gain importance in the future. There are several reasons for this. First, the treating surgeons should be able to objectively review the outcome of their patients and adapt the daily practice if necessary. The vast majority of surgeries are, however, nowadays still performed without an accurate breakdown of the quality of patient care for the individual surgeon [29]. Second, surgeons are obliged to inform the patients about benefits and surgical risks, especially if joint replacement is considered. The local arthroplasty data can be used to inform the patients on the basis of available objective data [4]. Third, some stakeholders express incremental interest in analyzing the value and benefits of different treatment modalities [28]. Governments and health care insurance providers start to challenge surgeon's indications, clearly showing the need for more high-level evidence to justify our daily clinical practice [28].

\section{Conclusion}

A well-managed institutional arthroplasty registry, including structured clinical and radiological follow-up assessments, offers the opportunity for high-quality long-term patient and arthroplasty outcome analysis. Such data are not only helpful to analyze the patient outcomes and implant survival, but will be increasingly important to justify our daily clinical practice against different stakeholders in the various health care systems. 


\section{Practical conclusion}

- The number of implanted RTSAs is increasing worldwide and requires a structured outcome analysis to optimize patient care.

- Local arthroplasty registries are a valuable tool for structured collection and compelling patient outcome data analysis.

- Local registries often allow a more focused analysis of the outcome of specific questions compared to national registries.

- REDCap is a valuable and effective tool for establishing an institutional registry.

- Categorization of data collection according to the necessary workload (basic and advanced data) has proven successful in clinical practice.

- An internationally standardized approach is recommended to achieve a high degree of comparability.

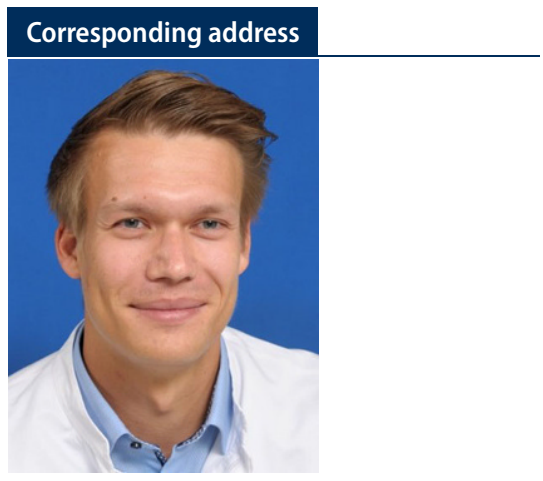

\section{Philipp Kriechling, MD}

Department of Orthopedics, Balgrist University Hospital

Forchstraße 340, 8008 Zurich, Switzerland philipp.kriechling@balgrist.ch

Funding. Open access funding provided by University of Zurich

\section{Declarations}

Conflict of interest. P. Kriechling, M. Waltenspül, S. Bouaicha, and K. Wieser declare that they have no competing interests.

All procedures performed in studies involving human participants or on human tissue were in accordance with the ethical standards of the institutional and/or national research committee and with the 1975 Helsinki declaration and its later amendments or comparable ethical standards (Cantonal Ethics Committee Zurich, ID 2018-01494). Informed consent was obtained from all individual participants included in the study.

Ethical approval The anonymous data collection and the study publication were approved by the cantonal ethics committee of the University of Zurich (ID 201801494) and conducted following the Helsinki Declara-

\section{Einrichtung eines institutionellen Registers für inverse Schultertotalendoprothesen}

Hintergrund: Die Zahl implantierter inverser Schultertotalprothesen (RTSA) ist international steigend. Um die Patientenversorgung zu verbessern, werden weltweit institutionelle und nationale Prothesenregister etabliert. Die vorliegende Arbeit beschreibt den Aufbau einer RTSA-Datenbank in einer orthopädischen Universitätsklinik mit hoher Fallzahl.

Methoden: Alle Patienten, welche eine RTSA an unserer Klinik erhielten, wurden seit 2005 nachkontrolliert und systematisch in einer REDCap-Datenbank erfasst. Die Übertragung erfolgt longitudinal als präoperative Erhebung und als reguläre oder irreguläre Verlaufskontrolle. Erfasst werden alle demographischen Basisdaten, die Patientenanamnese, die Operationsdetails, Prothesendetails, Komplikationen, radiologische und klinische Outcome-Scores (Constant-Murley-Score, Subjective Shoulder Value, Bewegungsmaße).

Ergebnisse: Im Zeitraum von Januar 2005 bis Dezember 2020 wurden insgesamt 1433 RTSA implantiert. Von diesen waren 1184 (83\%) primäre Implantationen und 249 (25\%) sekundäre Implantationen. Die Kohorte war im Mittel $70 \pm 10$ Jahre alt, zu $39 \%$ männlich und zu $59 \%$ als ASA II klassifiziert. Die Lost-to-follow-up-Rate betrug $18 \%$ nach 2 Jahren, $22 \%$ nach 5 Jahren und $53 \%$ nach 10 Jahren. Die generelle Komplikationsrate nach einem Mindest-Follow-up von 2 Jahren betrug 18\% (156/854 Schultern) mit notwendiger Revisionsoperation bei 10\% (82/854 Schultern). Schlussfolgerung: Ein sorgfältig geführtes lokales Endoprothesenregister mit strukturierten klinischen und radiologischen Nachuntersuchungen bietet die Möglichkeit einer qualitativ hochwertigen Langzeitanalyse der Patienten- und Endoprothesenergebnisse. Solche Daten sind nicht nur hilfreich für die Analyse des Patientenergebnisses und des Implantatüberlebens, sondern werden auch immer wichtiger in der Rechtfertigung unserer täglichen klinischen Praxis gegenüber verschiedenen Kostenträgern im Gesundheitssystem.

\section{Schlüsselwörter}

Rotatorenmanschettenverletzungen · Qualität der Gesundheitsversorgung · Datenbank · Postoperative Komplikationen · Behandlungsergebnisse

tion. Each patient treated at the clinic signed consent for further use of data for research following a detailed explanation.

Open Access. This article is licensed under a Creative Commons Attribution 4.0 International License, which permits use, sharing, adaptation, distribution and reproduction in any medium or format, as long as you give appropriate credit to the original author(s) and the source, provide a link to the Creative Commons licence, and indicate if changes were made. The images or other third party material in this article are included in the article's Creative Commons licence, unless indicated otherwise in a credit line to the material. If material is not included in the article's Creative Commons licence and your intended use is not permitted by statutory regulation or exceeds the permitted use, you will need to obtain permission directly from the copyright holder. To view a copy of this licence, visit http://creativecommons.org/licenses/by/4.0/.

\section{References}

1. Audigé L, Schwyzer H-K, Durchholz $\mathrm{H}$ et al (2019) Core set of unfavorable events of shoulder arthroplasty: an international Delphi consensus process. JShoulder Elbow Surg 28:2061-2071
2. Boileau P, Watkinson D, Hatzidakis AM et al (2006) Neer award 2005: the Grammont reverse shoulder prosthesis: results in cuff tear arthritis, fracture sequelae, and revision arthroplasty. J Shoulder Elbow Surg 15:527-540

3. Carpeggiani G, Hodel S, Götschi T et al (2020) Os acromiale in reverse total shoulder arthroplasty: a cohort study. Orthop J Sports Med 8:232596712096513

4. Chalmers PN, Boileau P, Romeo AA et al (2019) Revision reverse shoulder arthroplasty. J Am Acad Orthop Surg 27:426-436

5. Constant CR, Murley AH (1987) A clinical method of functional assessment of the shoulder. Clin Orthop Relat Res 214:160-164

6. Day JS, Lau E, Ong KL et al (2010) Prevalence and projections of total shoulder and elbow arthroplasty in the United States to 2015. JShoulderElbow Surg 19:1115-1120

7. Dubiel MJ, Kolz JM, Tagliero AJ et al (2021) Analysis of patient characteristics and outcomes related to distance traveled to a tertiary center for primary reverse shoulder arthroplasty. Arch Orthop Trauma Surg. https://doi.org/10.1007/s00402021-03764-9

8. Durchholz $\mathrm{H}$, Salomonsson $\mathrm{B}$, Moroder $\mathrm{P}$ et al (2019) Core set of radiographic parameters for shoulder arthroplasty monitoring: criteria defined 
by an international Delphi consensus process. JB JS Open Access 4:e25

9. Gerber C, Pennington SD, Nyffeler RW (2009) Reverse total shoulder arthroplasty. J Am Acad Orthop Surg 17:284-295

10. Gilbart MK, Gerber C (2007) Comparison of the subjective shoulder value and the Constant score. JShoulder Elbow Surg 16:717-721

11. Glanzmann MC, Audige L, Schwyzer HK et al (2020) Re-intervention and revision rates following primary reverse total shoulder arthroplasty—review of a local shoulder arthroplasty registry. Int Orthop 44:2365-2370

12. Gorman RA 2nd, Christmas KN, Simon Petal (2021) A cohort comparison of humeral implant designs in reverse shoulder arthroplasty: does implant design lead to lower rates of complications and revision? J Shoulder Elbow Surg 30:850-857

13. Grammont P, Trouilloud P, Laffay J et al (1987) Etude et réalisation d'une nouvelle prothèse d'épaule. Rhumatologie 39:407-418

14. Harris PA, Taylor R, Minor BLet al (2019) The REDCap consortium: Building an international community of software platform partners. J Biomed Inform 95:103208

15. Harris PA, Taylor R, Thielke R et al (2009) Research electronic data capture (REDCap) - a metadatadriven methodology and workflow process for providing translational research informatics support. J Biomed Inform 42:377-381

16. Kriechling $P$, Bouaicha $S$, Andronic $O$ et a (2020) Limited improvement and high rate of complication in patients undergoing reverse total shoulder arthroplasty for previous native shoulder infection. JShoulder Elbow Surg 30:34-39. https:// doi.org/10.1016/j.jse.2020.04.048

17. Kriechling $P$, Loucas $R$, Loucas $M$ et al (2021) Primary reverse total shoulder arthroplasty in patients older than 80 years: clinical and radiologic outcome measures. J Shoulder Elbow Surg 30:877-883

18. Lehtimaki K, Rasmussen JV, Kukkonen J et al (2020) Low risk of revision after reverse shoulder arthroplasty for acute proximal humeral fractures. JSES Int 4:151-155

19. Levigne C, Chelli M, Johnston Tet al (2021) Reverse shoulder arthroplasty in rheumatoid arthritis: survival and outcomes. J Shoulder Elbow Surg https://doi.org/10.1016/j.jse.2021.01.033

20. Lindbloom BJ, Christmas KN, Downes Ket al (2019) Is there a relationship between preoperative diagnosis and clinical outcomes in reverse shoulder arthroplasty? An experience in 699 shoulders. J Shoulder Elbow Surg 28:S110-S117

21. Malchau H, Garellick G, Berry D et al (2018) Arthroplasty implant registries over the past five decades: development, current, and future impact. J Orthop Res 36:2319-2330

22. Marzel A, Schwyzer HK, Kolling C et al (2020) The Schulthess local shoulder arthroplasty registry (SAR): cohort profile. BMJ Open 10:e40591

23. Page RS, Navarro RA, Salomonsson B (2014) Establishing an international shoulder arthroplasty consortium. J Shoulder Elbow Surg 23:1081-1082

24. Rasmussen JV, Brorson S, Hallan G et al (2016) Is it feasible to merge data from national shoulder registries? A new collaboration within the Nordic Arthroplasty Register Association. J Shoulder Elbow Surg 25:e369-e377

25. Registry AOa NJ (2020) Hip, knee \& shoulder arthroplasty report

26. Registry NJ (2020) NJR 17th annual report 2020, p17
27. Routman HD, Simovitch RW, Wright TW etal (2020) Acromial and scapular fractures after reverse total shoulder arthroplasty with a medialized glenoid and lateralized humeral implant: an analysis of outcomes and risk factors. J Bone Joint Surg Am 102:1724-1733

28. Tischer T, Lenz R, Breinlinger-O'Reilly J et al (2020) Cost analysis in shoulder surgery: a systematic review. Orthop JSports Med 8:2325967120917121

29. Zumstein MA, Pinedo M, Old J et al (2011) Problems, complications, reoperations, and revisions in reverse total shoulder arthroplasty: a systematic review. J Shoulder Elbow Surg 20:146-157 